Arq. Bras. Med. Vet. Zootec., v.66, n.5, p.1531-1538, 2014

\title{
Níveis de inclusão do farelo de arroz parboilizado em rações para leitões na fase de creche
}

\author{
[Inclusion levels of parboiled rice bran in piglet diets in the nursery phase] \\ T.M.F. Aquino, P.H. Watanabe, L.E. Carvalho, E.R. Freitas, R.C. Nepomuceno, E.L. Oliveira, \\ T.R. Gomes, E.A.C. Ellery, K.M. Santos, A.S. Pereira, G.C. Aguiar \\ Universidade Federal do Ceará - UFC - Centro de Ciências Agrárias- Fortaleza, CE
}

\section{RESUMO}

Foram conduzidos dois ensaios para avaliar a utilização do farelo do farelo integral de arroz parboilizado (FIAP) em rações para leitões na fase de creche. No primeiro, foram utilizados 14 suínos machos castrados para a avaliação nutricional do ingrediente em ensaio de digestibilidade. $\mathrm{O}$ delineamento experimental foi o inteiramente ao acaso, com dois tratamentos e sete repetições por tratamento. O FIAP apresenta 17,15\% de PB, elevado teor em fibras (33,75\% de FDN e 15,91\% de FDA) e teor reduzido de energia metabolizável, próximo a $2320 \mathrm{kcal} / \mathrm{kg}$. No segundo experimento, foram utilizados 60 leitões machos castrados, com o objetivo de avaliar o desempenho zootécnico, a ocorrência de diarreia e a viabilidade econômica do farelo de arroz parboilizado. $\mathrm{O}$ delineamento experimental foi em blocos ao acaso, com cinco tratamentos $(0,4,8,12$ e $16 \%$ de inclusão) e seis repetições. Não houve diferença significativa entre o tratamento controle e os tratamentos teste ( $\mathrm{P}>0,05)$, assim como para a análise de regressão, em que os crescentes níveis de inclusão do ingrediente não resultaram em piora no desempenho $(\mathrm{P}>0,05)$. O FIAP pode ser incluído até o nível de $16 \%$ em rações para leitões na fase de creche.

Palavras-chave: análise econômica, desempenho, ocorrência de diarreia, subproduto do arroz, suínos

\begin{abstract}
Two assays were conducted to evaluate the parboiled rice bran in piglet's diets in the nursery phase. In the first, 14 male castrated piglets were allotted to determine the nutritional value of parboiled rice bran in a digestibility assay. A completely randomized design, with 2 treatments and 7 replicates per treatment were used. The parboiled rice bran presents $17.15 \%$ of CP and high fiber content (33.75\% of NDF and $15.91 \%$ of $A D F)$ and low metabolizable energy (2320kcal $/ \mathrm{kg})$. In the second assay, 60 male castrated piglets were used to evaluate the effect of inclusion on productive performance, diarrhea incidence and economic viability of parboiled rice bran. A randomized block design was used, with 5 treatments $(0,4,8$, 12 and 16\%) and 6 replicates. There was no difference between treatments and control treatment as well as in regression analysis, and the increasing levels of parboiled rice bran did not reduce the performance of animals. In conclusion, parboiled rice bran can be included up to $16 \%$ in diets for piglets in the nursery phase.
\end{abstract}

Keyword: economic analysis, occurrence of diarrhea, performance, pigs, rice by-product

\section{INTRODUÇÃO}

O desmame é um período crítico para o leitão, cujas mudanças sociais e ambientais, bem como as alterações tanto de ordem nutricional quanto alimentar, são os principais fatores estressantes aos animais, acarretando em redução no consumo e, consequentemente, em maior incidência de doenças entéricas (Pluske et al., 1997).

Recebido em 1 de fevereiro de 2013

Aceito em 19 de fevereiro de 2014

E-mail: pedrowatanabe@ufc.br

Projeto Financiado pelo Banco do Nordeste 
Assim, a transição da alimentação à base de leite materno para uma dieta sólida, que se inicia ainda na fase de maternidade, consolida-se na fase de creche, quando então os leitões deverão estar adaptados a essa única fonte de nutrientes. Além disso, apesar do consumo de ração reduzido, o custo da alimentação ainda na fase de creche é elevado devido à inclusão de ingredientes de elevadas digestibilidade e densidade nutricional (Lima et al., 2009).

Dessa forma, ao se buscar a redução dos custos com alimentação dos leitões na fase de creche, as margens para essa redução implicariam a procura por substitutos ao milho e ao farelo de soja, em razão dos custos e da participação destes nas rações. Embora pouco usual, a utilização de alimentos alternativos em rações para leitões pode ser viável (Nepomuceno et al., 2011), porém há necessidade de avaliá-los primariamente e não se recomenda extrapolar os valores nutricionais e energéticos obtidos para animais de outras categorias.

Entre os subprodutos da indústria, destacam-se os resíduos da indústria rizícola, como o farelo integral de arroz parboilizado (FIAP), oriundo do processo de parboilização, que consiste em um processo térmico aplicado no arroz antes do descascamento e do polimento, a fim de aumentar a renda de beneficiamento, esterilizar o grão e aumentar a vida útil de prateleira (Nitzke, 2004). Em razão do processamento, há diferença na composição nutricional do FIAP quando comparado ao farelo de arroz integral, sendo evidenciado principalmente maior teor de extrato etéreo e menor para amido disponível (Denardin et al., 2003).

Embora o farelo de arroz integral já seja comumente utilizado em rações para não ruminantes, verifica-se a inexistência de estudos em relação ao FIAP para suínos. Assim, com o presente trabalho, objetivou-se avaliar a utilização do FIAP em rações para leitões na fase de creche quanto à composição nutricional e energética do ingrediente e sobre o desempenho, a ocorrência de diarreia e a avaliação econômica.

\section{MATERIAL E MÉTODOS}

Para avaliar a digestibilidade dos nutrientes e a metabolizabilidade da energia do FIAP, utilizaram-se 14 leitões machos castrados, de linhagem comercial, com peso inicial de $17,2 \pm 1,02 \mathrm{~kg}$, alojados em gaiolas para estudos metabólicos.

Foram utilizados dois tratamentos: uma dieta referência à base de milho, farelo de soja, soro de leite permeado em pó e leite desnatado em pó; e uma dieta teste $(70 \%$ da dieta referência $+30 \%$ do FIAP). Ambas as dietas foram formuladas para atender as exigências nutricionais mínimas de acordo com Rostagno et al. (2011).

O experimento teve duração de 12 dias, sendo sete para adaptação dos animais às gaiolas e determinação do consumo de ração e cinco para as coletas de fezes e urina. $\mathrm{O}$ arraçoamento foi realizado às oito e às 17 horas. A quantidade de ração fornecida no período de coleta das fezes foi definida de acordo com o menor consumo obtido durante os sete dias iniciais, baseado no peso metabólico $\left(\mathrm{kg}^{0,75}\right)$ de cada animal, e a água foi fornecida à vontade. Utilizou-se como marcador fecal o óxido férrico $\left(\mathrm{Fe}_{2} \mathrm{O}_{3}\right)$. Foi utilizado o método de coleta total de fezes e urina, sendo as fezes recolhidas e pesadas em sacos plásticos duas vezes ao dia e armazenadas a $-8^{\circ} \mathrm{C}$ para posterior análise. A urina foi coletada uma vez ao dia, em baldes plásticos, contendo $20 \mathrm{~mL}$ de solução de água destilada e ácido clorídrico (1:1). O volume de urina produzida foi mensurado, e retirou-se uma alíquota de $20 \%$, que foi mantida congelada.

Ao final do experimento, as fezes foram descongeladas e homogeneizadas para a obtenção de uma amostra, composta de aproximadamente $200 \mathrm{~g}$, submetidas à présecagem, em estufa de circulação de ar forçada a $55^{\circ} \mathrm{C}$ durante 72 horas, e posteriormente moídas em moinho de facas com peneira com crivos de $1 \mathrm{~mm}$. As amostras de urina foram secas em placas de Petri, em estufa com circulação de ar forçada a $55^{\circ} \mathrm{C}$ por 72 horas, e a cada 24 horas o volume das placas foi completado.

As amostras das rações, fezes e urina foram analisadas para determinação dos teores de matéria seca (MS), matéria mineral (MM), proteína bruta $(\mathrm{PB})$, extrato etéreo (EE), de acordo com Silva e Queiróz (2002), fibra em detergente neutro (FDN) e fibra em detergente ácido (FDA), conforme Van Soest et al. (1991), e energia bruta (EB), utilizando-se bomba calorimétrica adiabática (PARR modelo 
1241EA). Posteriormente, foram calculados os coeficientes de digestibilidade (CD) dos nutrientes e da energia metabolizável (EM) do FIAP, empregando-se as fórmulas descritas por Sakomura e Rostagno (2007). Os valores de PB e EM do FIAP foram utilizados para a formulação das rações do ensaio de desempenho.

Para avaliar o desempenho zootécnico e a viabilidade econômica da inclusão de diferentes níveis do FIAP, foram utilizados 60 suínos machos castrados, de linhagem comercial, desmamados aos 21 dias de idade e com peso inicial de $6,40 \pm 0,79 \mathrm{~kg}$, distribuídos em delineamento em blocos ao acaso, com cinco tratamentos $(0,4,8,12$ e $16 \%$ de inclusão do FIAP) e seis repetições, sendo dois animais por unidade experimental.

As rações (Tab. 1) foram calculadas considerando-se as fases I (21 a 32 dias); II (33 a 42 dias) e III (43 a 63 dias). Como não houve redistribuição dos animais ao final de cada fase, para a análise dos dados consideraram-se o período I (21 a 32 dias), o II (21 a 42 dias) e o total (21 a 63 dias). Para a composição das rações, foram utilizados os dados das análises químico-bromatológicas do milho, do farelo de soja, do FIAP, do soro de leite permeado em pó e do leite desnatado em pó.

Tabela 1. Composição percentual e custo das rações experimentais que utilizaram farelo de arroz parboilizado (FIAP) para leitões nas fases inicial I (21-32 dias de idade), inicial II (21-42 dias) e inicial III (21 a 63 dias de idade)

\begin{tabular}{|c|c|c|c|c|c|c|c|c|c|c|c|c|c|c|c|}
\hline \multirow[t]{3}{*}{ Ingredientes } & \multicolumn{15}{|c|}{ Níveis de farelo de arroz parboilizado } \\
\hline & \multicolumn{5}{|c|}{$\begin{array}{c}\text { Fase inicial I ( } 21 \text { a } 32 \\
\text { dias de idade) }\end{array}$} & \multicolumn{5}{|c|}{ Fase inicial II (21 a 42 dias de idade) } & \multicolumn{5}{|c|}{ Fase inicial III (21 a 63 dias de idade) } \\
\hline & $0 \%$ & $4 \%$ & $8 \%$ & $12 \%$ & $16 \%$ & $0 \%$ & $4 \%$ & $8 \%$ & $12 \%$ & $16 \%$ & $0 \%$ & $4 \%$ & $8 \%$ & $12 \%$ & $16 \%$ \\
\hline Farelo de soja & 33,35 & 32,39 & 31,23 & 30,08 & 29,00 & 36,10 & 35,27 & 34,12 & 32,96 & 31,70 & 26,09 & 24,94 & 23,78 & 22,63 & 21,49 \\
\hline & 0,00 & 4,00 & 8,00 & 12,00 & 16,00 & 0,00 & 4,00 & 8,00 & 12,00 & 16,00 & 0,00 & 4,00 & 8,00 & 12,00 & 16,00 \\
\hline $\begin{array}{l}\text { Soro } \\
\text { p.pó }^{1}\end{array}$ & 6,00 & 6,00 & 6,00 & 6,00 & 6,00 & 4,00 & 4,00 & 4,00 & 4,00 & 4,00 & 2,00 & 2,00 & 2,00 & 2,00 & 2,00 \\
\hline Óleo de soja & 5,50 & 5,70 & 5,70 & 5,70 & 5,70 & 5,10 & 5,44 & 5,44 & 5,44 & 5,44 & 1,70 & 1,70 & 1,70 & 1,70 & 1,70 \\
\hline Fosfato bicálcico & 1,88 & 1,87 & 1,86 & 1,85 & 1,84 & 1,59 & 1,58 & 1,57 & 1,55 & 1,54 & 1,30 & 1,29 & 1,27 & 1,26 & 1,25 \\
\hline Calcário & 0,87 & 0,88 & 0,89 & 0,90 & 0,90 & 0,94 & 0,95 & 0,96 & 0,96 & 0,97 & 0,97 & 0,97 & 0,98 & 0,99 & 1,00 \\
\hline L-Lisina $\mathrm{HCl}$ & 0,56 & 0,60 & 0,64 & 0,68 & 0,72 & 0,31 & 0,34 & 0,38 & 0,43 & 0,47 & 0,28 & 0,32 & 0,37 & 0,41 & 0,45 \\
\hline Sup. vit. $\min ^{3 *}$ & 0,40 & 0,40 & 0,40 & 0,40 & 0,40 & 0,40 & 0,40 & 0,40 & 0,40 & 0,40 & 0,40 & 0,40 & 0,40 & 0,40 & 0,40 \\
\hline Sal comum & 0,48 & 0,48 & 0,48 & 0,49 & 0,49 & 0,40 & 0,40 & 0,41 & 0,41 & 0,41 & 0,39 & 0,39 & 0,40 & 0,40 & 0,40 \\
\hline \multicolumn{16}{|c|}{ Composição nutricional** } \\
\hline $\mathrm{EM}^{4}, \mathrm{Mcal} / \mathrm{kg}$ & 3,40 & 3,40 & 3,40 & 3,40 & 3,40 & 3,37 & 3,37 & 3,37 & 3,37 & 3,37 & 3,23 & 3,23 & 3,23 & 3,23 & 3,23 \\
\hline $\mathrm{PB}^{5}, \%$ & 20,00 & 20,00 & 20,00 & 20,00 & 20,00 & 21,00 & 21,00 & 21,00 & 21,00 & 21,00 & 18,13 & 18,13 & 18,13 & 18,13 & 18,13 \\
\hline Fosf.disp. ${ }^{6}, \%$ & 0,50 & 0,50 & 0,50 & 0,50 & 0,50 & 0,45 & 0,45 & 0,45 & 0,45 & 0,45 & 0,36 & 0,36 & 0,36 & 0,36 & 0,36 \\
\hline Cálcio (\%) & 0,85 & 0,85 & 0,85 & 0,85 & 0,85 & 0,83 & 0,83 & 0,83 & 0,83 & 0,83 & 0,73 & 0,73 & 0,73 & 0,73 & 0,73 \\
\hline Lis.dig. ${ }^{7}(\%)$ & 1,45 & 1,45 & 1,45 & 1,45 & 1,45 & 1,33 & 1,33 & 1,33 & 1,33 & 1,33 & 1,04 & 1,04 & 1,04 & 1,04 & 1,04 \\
\hline Met+cis.dig. ${ }^{8}(\%)$ & 0,81 & 0,81 & 0,81 & 0,81 & 0,81 & 0,74 & 0,74 & 0,74 & 0,74 & 0,74 & 0,58 & 0,58 & 0,58 & 0,58 & 0,58 \\
\hline
\end{tabular}

${ }^{1}$ Soro de leite permeado em pó; ${ }^{2}$ leite desnatado em pó; ${ }^{3}$ suplemento vitamínico e mineral; ${ }^{4}$ energia metabolizável; ${ }^{5}$ proteína bruta;

${ }^{6}$ fósforo disponível; ${ }^{7}$ lisina digestível; ${ }^{8}$ metionina+cistina disponível.

* Suplemento vitamínico-mineral - quantidade por kg do produto: 1.500.000UI de vitamina A, 450.000UI de vitamina D3, 22,50 $\mathrm{mg}$ de biotina, $68 \mathrm{mg}$ de colina, $7.500 \mathrm{mg}$ de niacina, $4.500 \mathrm{mg}$ de pantotenato de cálcio, $5.000 \mathrm{mg}$ de vitamina B12, $1.300 \mathrm{mg}$ de vitamina B2, 7.500mg de vitamina E, 1.500mg de vitamina K3, 12,5g de ferro, 5.250mg de cobre, 8.750mg de manganês, 26,25g de zinco, $350 \mathrm{mg}$ de iodo, $75 \mathrm{mg}$ de selênio.

**De acordo com a recomendação de Rostagno et al. (2011).

Durante o ensaio de desempenho, os animais receberam ração à vontade, e as sobras foram recolhidas diariamente. Ao final de cada fase, os animais foram pesados, e as sobras quantificadas, determinando-se o ganho de peso médio diário (GPMD), o consumo de ração médio diário (CRMD) e a conversão alimentar (CA).
A avaliação da ocorrência de diarreia foi realizada por meio da avaliação das fezes dos dois leitões da parcela, durante os primeiros 21 dias do período experimental, classificadas em: escore 1 - fezes com consistência normal; 2 fezes pastosas; e 3 - fezes moles ou aquosas, sendo esse período considerado como presença de diarreia (Huaynate et al., 2006). 
Os custos dos ingredientes utilizados na composição das rações experimentais foram obtidos na região metropolitana de Fortaleza, em novembro de 2011, sendo $\mathrm{R} \$ 0,70 / \mathrm{kg}$ de milho; $\mathrm{R} \$ 0,98 / \mathrm{kg}$ de farelo de soja; $\mathrm{R} \$ 0,53 / \mathrm{kg}$ de FIAP; $\mathrm{R} \$ 12,45 / \mathrm{kg}$ de leite desnatado em pó; $\mathrm{R} \$ 2,99 / \mathrm{kg}$ de soro de leite permeado em pó; $\mathrm{R} \$ 1,57 / \mathrm{kg}$ de açúcar; R $\$ 2,74 / \mathrm{kg}$ de óleo de soja bruto; $\mathrm{R} \$ 3,00 / \mathrm{kg}$ de fosfato bicálcico; $\mathrm{R} \$ 0,18 / \mathrm{kg}$ de calcário calcítico; $\mathrm{R} \$ 0,36 / \mathrm{kg}$ de sal comum; $\mathrm{R} \$ 5,87 / \mathrm{kg}$ de lisina-HCl; $\mathrm{R} \$ 9,92 / \mathrm{kg}$ de DLmetionina; $\mathrm{R} \$ 6,66 / \mathrm{kg}$ de suplemento mineral e vitamínico; $\mathrm{R} \$ 300,00 / \mathrm{kg}$ de BHT.

A avaliação econômica da inclusão do FIAP nas rações foi determinada pelo custo da ração $(\mathrm{CR})$ por quilograma de ganho de peso vivo, segundo equação proposta por Bellaver et al. (1985). Em seguida, foram calculados o índice de eficiência econômica (IEE) e o índice de custo (IC) propostos por Fialho et al. (1992).

A análise estatística dos dados foi realizada por meio do procedimento de PROC GLM do software SAS (Statistical..., 2001). Os dados de desempenho zootécnico e a viabilidade econômica foram submetidos à análise de regressão, excluindo-se a ração sem inclusão do FIAP para descrever o efeito sobre as variáveis. Para comparação dos resultados obtidos com cada um dos níveis de inclusão do FIAP em relação à ração sem inclusão do ingrediente, foi utilizado o teste de Dunnett (5\%). Para a ocorrência de diarreia, foi utilizada a estatística não paramétrica, e as médias foram comparadas pelo teste de Kruskall-Wallis (5\%).

\section{RESULTADOS E DISCUSSÃO}

Ao se avaliar a composição química do ingrediente por meio do ensaio de digestibilidade, o FIAP apresentou maior teor de PB, EE, FDN e FDA e menor concentração de EM (Tab. 2) em comparação aos valores encontrados por Rostagno et al. (2011). Assim, embora o teor de EE seja elevado e esta fração apresente elevado coeficiente de digestibilidade, observou-se efeito reducional sobre a concentração energética desse ingrediente, possivelmente devido à presença de componentes fibrosos de baixa digestibilidade.

Tabela 2. Composição química, coeficientes de digestibilidade e metabolizabilidade, nutrientes digestíveis e energia metabolizável do farelo de arroz parboilizado

\begin{tabular}{lccc}
\hline $\begin{array}{c}\text { Nutrientes e } \\
\text { energia }\end{array}$ & $\begin{array}{c}\text { Composição } \\
\text { química }\end{array}$ & $\begin{array}{c}\text { Coeficientes de digestibilidade e } \\
\text { metabolizabilidade }\end{array}$ & $\begin{array}{c}\text { Nutrientes digestíveis e } \\
\text { energia metabolizável }\end{array}$ \\
\hline MS (\%) & 93,74 & 61,61 & 57,75 \\
MM (\%) & 3,12 & 4,23 & 0,13 \\
FDN (\%) & 33,75 & 8,45 & 2,85 \\
FDA (\%) & 15,91 & 5,72 & 0,91 \\
EE (\%) & 27,33 & 91,30 & 24,95 \\
PB (\%) & 17,15 & 64,39 & 11,04 \\
EB (kcal/kg) & 4108,62 & 56,49 & 2321,08
\end{tabular}

${ }^{1} \mathrm{MS}(\%)=$ matéria seca; $\mathrm{MM}(\%)=$ matéria mineral; $\mathrm{FDN}(\%)=$ fibra em detergente neutro; $\mathrm{FDA}(\%)=$ fibra em detergente ácido; $\mathrm{EE}(\%)=$ extrato etéreo; $\mathrm{PB}(\%)=$ proteína bruta; $\mathrm{EB}(\mathrm{kcal} / \mathrm{kg})=$ energia bruta.

Considerando-se as frações amiláceas como as de maior digestibilidade e contribuição energética dentre os carboidratos, observou-se menor coeficiente de digestibilidade da matéria seca do FIAP em comparação ao da silagem de milho para leitões (Oliveira et al., 2004), possivelmente em virtude da maior proporção de amilose em relação à amilopectina do ingrediente. De acordo com Denardin e Silva (2009) a amilose apresenta menor digestibilidade devido a sua característica físico-química de menor capacidade de hidratação, quando comparada à amilopectina de natureza amorfa. Os menores valores para os CD da MS e PB, quando comparados aos obtidos por Rostagno et al. (2011) para o farelo de arroz integral, são decorrentes da diferença existente entre os subprodutos do arroz e os tratamentos pelos quais são submetidos. Além disso, os trabalhos que avaliam a composição e o valor nutricional 
dos alimentos para suínos são, em sua maioria, com animais nas fases de crescimento e/ou terminação, períodos de maior maturidade fisiológica dos animais, que, dessa forma, estão mais adaptados a ingredientes com maior participação em componentes fibrosos. Portanto, por não levar em consideração as diferenças existentes entre as categorias, o uso de valores nutricionais e energéticos encontrados em tabelas de composição de alimentos pode incorrer em erro na formulação de rações. Assim, principalmente no caso de dietas para leitões, a utilização de ingredientes alternativos deve ser avaliada não só quanto à composição química, mas também em relação à digestibilidade dos nutrientes e à metabolizabilidade da energia.

Em relação ao desempenho, para a análise de regressão, não houve efeito para nenhuma das variáveis em função dos níveis de inclusão de FIAP para todos os períodos avaliados (Tab. 3). Também não houve diferença entre os animais alimentados com ração sem FIAP em comparação com aqueles alimentados com diferentes níveis de inclusão $(\mathrm{P}>0,05)$ para os períodos de 21 a 32 e de 21 a 42 dias de idade, o que, possivelmente, foi determinado pelo alto coeficiente de variação nos parâmetros avaliados, sendo este resultante do estresse pós-desmame e das condições de alojamento no período. No entanto, para o período total (21 a 63 dias de idade), observou-se que a inclusão de 12 e $16 \%$ do FIAP resultou em uma melhor CA dos animais quando comparados àqueles alimentados com ração sem a inclusão do FIAP. Da mesma forma, Oliveira et al. (2012) não observaram efeito da substituição parcial do farelo de soja por proteína concentrada de soja para leitões no período inicial da fase de creche, porém notaram melhor conversão alimentar no período total, em razão do menor coeficiente de variação resultante do menor efeito do ambiente sobre o animal.

Valores próximos em relação à utilização de subprodutos do arroz foram encontrados por Gomes et al. (2012), que, ao avaliarem o FAI para leitões na fase de creche, recomendaram o nível máximo de utilização do ingrediente de $20 \%$. Outros subprodutos do arroz, por sua composição nutricional, podem ser incluídos em maiores níveis de inclusão em rações para leitões. Nepomuceno et al. (2011) avaliaram a quirera de arroz e concluíram que tal produto seria viável até o nível de $56 \%$ de inclusão durante a fase de creche.

Tabela 3. Desempenho zootécnico dos leitões na fase de creche (21 aos 32 dias de idade, 21 aos 42 dias de idade e 21 aos 63 dias de idade) alimentados com dietas que continham diferentes níveis de inclusão de farelo de arroz parboilizado

\begin{tabular}{lcccccc}
\hline \multirow{2}{*}{ Bloco } & \multicolumn{7}{c}{ Níveis de inclusão de farelo de arroz parboilizado (\%) } & \multirow{2}{*}{ Médias } \\
\cline { 2 - 5 } & 0,0 & 4,0 & 8,0 & 12,0 & 16,0 & \\
\hline CRMD (kg) & 0,15 & 0,15 & 0,14 & 0,15 & 0,15 & $\mathrm{CV}^{1}=15,35 \%$ \\
GPMD (kg) & 0,09 & 0,08 & 0,08 & 0,09 & 0,08 & $\mathrm{CV}^{1}=17,15 \%$ \\
CA (kg/kg) & 1,70 & 1,75 & 1,75 & 1,70 & 1,70 & $\mathrm{CV}^{1}=16,17 \%$ \\
\hline \multicolumn{7}{c}{21 aos 42 dias de idade } \\
\hline CRMD (kg) & 0,26 & 0,27 & 0,24 & 0,28 & 0,23 & $\mathrm{CV}^{1}=32,01 \%$ \\
GPMD (kg) & 0,15 & 0,16 & 0,14 & 0,17 & 0,14 & $\mathrm{CV}^{1}=28,13 \%$ \\
CA (kg/kg) & 1,73 & 1,69 & 1,71 & 1,64 & 1,64 & $\mathrm{CV}^{1}=18,09 \%$ \\
\hline \multicolumn{7}{c}{21 aos 63 dias de idade } \\
\hline CRMD (kg) & 0,52 & 0,54 & 0,49 & 0,52 & 0,52 & $\mathrm{CV}^{1}=14,23 \%$ \\
GPMD (kg) & 0,26 & 0,30 & 0,26 & 0,30 & 0,29 & $\mathrm{CV}^{1}=21,88 \%$ \\
CA (kg/kg) & 1,99 & 1,82 & 1,88 & $1,72 *$ & $1,75 *$ & $\mathrm{CV}^{1}=7,90 \%$ \\
\hline
\end{tabular}

*Comparação significativa pelo teste de Dunnett (5\%); ${ }^{1}$ coeficientes de variação. 
Para a ocorrência de diarreia (Tab. 4), foram desconsiderados os três primeiros dias do período de avaliação em razão da ausência de fezes em mais da metade das unidades experimentais. Não houve diferença significativa $(\mathrm{P}>0,05)$ entre os tratamentos. Os resultados obtidos no presente trabalho corroboram os encontrados por Nepomuceno et al. (2011) e Gomes et al. (2012), ao avaliarem outros subprodutos do arroz em rações para leitões quanto à ocorrência de diarreia. Embora McDonald et al. (1999) e Montagne et al. (2004) afirmem que a cocção do arroz resulta em proteção contra colibacilose pós-desmame em leitões, observou-se maior incidência de diarreia naqueles alimentados com dietas contendo FIAP.

Apesar de a diarreia em leitões ser de ordem multifatorial, a maior participação da fibra na ração poderia acentuar aquelas de causa nutricional devido à aceleração no trânsito intestinal, que promove menor tempo de digestão e absorção do alimento e, consequentemente, faz com que o conteúdo seja propelido em direção à parte final do intestino (Lima et al., 2009). Nesse sentido, a prevalência de fezes pastosas e moles dos animais alimentados com ração contendo 12 e $16 \%$ de FIAP poderia ser um indicativo da não utilização de níveis acima de $10 \%$ nas rações para leitões até os 42 dias de idade, em virtude da imaturidade fisiológica do sistema digestório a ingredientes com elevado teor de fibra, como o FIAP. Da mesma forma, segundo Palipane e Swarnasiri (1985), o FIAP possui teor de FB próximo a $11 \%$, enquanto o milho possui entre 2 e 3\%; assim, em decorrência do uso de até $16 \%$ de FIAP, a maior participação da fibra poderia causar diarreia nos leitões. Outro fator preponderante para a ocorrência de diarreia nutricional observado no presente trabalho seria o maior teor de amilose em detrimento da amilopectina nas dietas contendo o FIAP, o que poderia resultar na maior osmolaridade luminal e, por conseguinte, proporcionar maior secreção de fluidos para o lúmen intestinal dos leitões. No entanto, tais efeitos da adição do FIAP seriam minimizados com o aumento da idade do animal, conforme pode ser verificado com a melhor conversão alimentar dos animais no período total da fase de creche (Tab. 3).

Tabela 4. Escores fecais e ocorrência de diarreia em leitões alimentados com dietas com diferentes níveis de farelo de arroz parboilizado

\begin{tabular}{cccccccc}
\hline \multirow{2}{*}{ Escore fecal } & \multicolumn{9}{c}{ Nível de inclusão de farelo de arroz parboilizado } & \multirow{2}{*}{ Total } & \multirow{2}{*}{ \% Escore } \\
\cline { 2 - 6 } & 0 & 4 & 8 & 12 & 16 & & \\
\hline 1 & 13 & 17 & 12 & 5 & 5 & 52 & 9,63 \\
2 & 52 & 48 & 47 & 55 & 52 & 254 & 47,04 \\
Total & 43 & 43 & 49 & 48 & 51 & 234 & 43,33 \\
\% de escore 3* & 108 & 108 & 108 & 108 & 108 & 540 & 100 \\
\hline
\end{tabular}

1: fezes normais; 2 : fezes pastosas; 3 : fezes aquosas. * Porcentagem de fezes diarreicas.

Os resultados da avaliação econômica em função dos níveis de FIAP estão apresentados na Tab. 5. Para todos os períodos analisados, verificou-se que a inclusão de FIAP não resultou em diferença em relação aos animais alimentados sem a inclusão do ingrediente para as variáveis de CR, IC e IEE. De acordo com a análise de regressão, não houve efeito significativo $(\mathrm{P}>0,05)$ entre os níveis de inclusão do FIAP para as variáveis de viabilidade econômica estudadas.

A utilização de subprodutos de arroz em substituição ao milho e/ou ao farelo de soja pode melhorar os resultados econômicos da produção de suínos em que o custo dos subprodutos seja menor que os custos destes e a disponibilidade desses ingredientes permita a substituição total ou parcial nas rações sem afetar os parâmetros zootécnicos. No presente trabalho, o custo do FIAP foi de aproximadamente $75,71 \%$ do custo do milho e de $54,08 \%$ em relação ao custo do farelo de soja, o que permitiu o incremento dos níveis de óleo de soja nas rações para mantê-las isonutrientes, em virtude do valor de energia metabolizável inferior ao desses ingredientes. Da mesma forma, ao substituírem totalmente o milho por farinha de trigo ou quirera de arroz como fonte de amido em rações para leitões na fase de creche, Ebert et al. (2005) observaram que ambas as fontes de carboidratos apresentaram-se mais vantajosas economicamente, mesmo com a adição de óleo vegetal para manter as dietas isoenergéticas. Em 
razão da eficiência e do baixo consumo na fase de creche, considera-se que variações na quantidade de ração para produzir $1 \mathrm{~kg}$ de peso vivo é o principal fator que influencia o custo de produção nessa fase (Carroll et al., 1971). Nesse sentido, em virtude da composição bromatológica e considerando que o desempenho e o custo da alimentação dos leitões alimentados com $16 \%$ de inclusão do FIAP não diferiram significativamente ao obtido para o grupo controle, esse ingrediente pode substituir parcialmente o milho e o farelo de soja em rações até o nível de $16 \%$.

Tabela 5. Avaliação econômica dos custos de leitões na fase de creche ( 21 aos 32 dias de idade, 21 aos 42 dias de idade e 21 aos 63 dias de idade) com diferentes níveis de inclusão de farelo de arroz parboilizado

\begin{tabular}{lcccccc}
\hline \multirow{2}{*}{ Bloco } & \multicolumn{7}{c}{ Níveis de inclusão de farelo de arroz parboilizado (\%) } & \multirow{2}{*}{ CV $^{1}, \%$} \\
\cline { 2 - 5 } & 0,0 & 4,0 & 8,0 & 12,0 & 16,0 & \\
\hline Cte $(\mathrm{R} \$ / \mathrm{Kg})$ & 2,90 & 3,00 & 2,91 & 2,95 & 2,93 & $15,58 \%$ \\
IEE $(\%)$ & 75,03 & 73,20 & 74,67 & 72,83 & 73,70 & $15,08 \%$ \\
IC $(\%)$ & 136,19 & 141,01 & 136,40 & 138,36 & 137,74 & $15,58 \%$ \\
\hline \multicolumn{7}{c}{21 aos 42 dias de idade } \\
\hline Cte $(\mathrm{R} \$ / \mathrm{Kg})$ & 2,48 & 2,26 & 2,25 & 2,37 & 2,24 & $12,90 \%$ \\
IEE $(\%)$ & 70,99 & 77,34 & 77,83 & 74,52 & 74,80 & $15,30 \%$ \\
IC $(\%)$ & 143,21 & 130,76 & 129,98 & 136,66 & 129,50 & $12,90 \%$ \\
\hline \multicolumn{7}{c}{21 aos 63 dias de idade } \\
\hline Cte $(\mathrm{R} \$ / \mathrm{kg})$ & 2,21 & 2,19 & 2,16 & 2,23 & 2,23 & $4,40 \%$ \\
IEE $(\%)$ & 107,42 & 106,40 & 104,87 & 108,24 & 108,06 & $4,40 \%$ \\
IC $(\%)$ & 93,20 & 94,06 & 95,44 & 92,59 & 92,81 & $4,23 \%$ \\
\hline
\end{tabular}

Médias comparadas pelo teste de Dunnett (5\%); ${ }^{1}$ coeficientes de variação.

\section{CONCLUSÃO}

O FIAP apresenta $17,15 \%$ de PB, elevado teor em fibras $(33,75 \%$ de FDN e $15,91 \%$ de FDA) e teor reduzido de energia metabolizável, próximo a $2320 \mathrm{kcal} / \mathrm{kg}$, portanto pode ser utilizado em rações para leitões na fase de creche até o nível de $16 \%$.

\section{AGRADECIMENTOS}

Ao Banco do Nordeste - ETENE/Fundeci, pelo financiamento do projeto.

\section{REFERÊNCIAS}

BELLAVER, C.; FIALHO, E.T.; PROTAS, J.F.S.; GOMES, P.C. Radícula de malte na alimentação de suínos em crescimento e terminação. Pesq. Agropec. Bras., v.20, p.969-974, 1985.

CARROLL, W.E.; KRIDER, J.L.; ANDREWS, F.N. Swine Production. New York: McGraw-Hill Book Company, 1971. 433p.
DENARDIN, C.C.; SILVA, L.P.; BEVILAQUA, P.R. et al. Composição nutricional do farelo de arroz polido e parboilizado. In: III Congresso Brasileiro de Arroz Irrigado e XXV Reunião da Cultura do Arroz Irrigado, 2003, Balneário Camboriú - SC. Anais. Itajaí - SC: Estação Experimental de Itajaí/ EPAGRI S. A., p.614-616. 2003.

DENARDIN, C.C.; SILVA, L.P. Estrutura dos grânulos de amido e sua relação com propriedades físico-químicas. Cienc. Rural, Santa Maria, v.39, p.945-954, 2009.

EBERT, A.R.; RIBEIRO, A.M.L.; KESSLER, A.M. Desempenho e digestibilidade de leitões recém desmamados recebendo grãos de arroz, milho ou farinha de trigo escura. Arch. Latinoam. Prod. Anim., v.13, p.43-50, 2005.

FIALHO, E.T.; BARBOSA, O.; FERREIRA, A.S.; et al. Utilização da cevada suplementada com óleo de soja para suínos em crescimento e terminação. Pesq. Agropec. Bras., v.27, p.1467-1475, 1992.

GOMES, T.R.; CARVALHO, L.E.; FREITAS, E.R. et $a l$. Efeito da inclusão de farelo de arroz integral em rações para leitões de 21 a 42 dias de idade. Arch. Zootec., v.61, p.129-139, 2012. 
HUAYNATE, R.A.R.; THOMAZ, M.C.; KRONKA, R.N. et al. Uso de probiótico em dietas de suínos incidência de diarreia, desempenho zootécnico e digestibilidade de rações. Braz. J. Vet. Res. Anim. Sci., v.43, p.664-673, 2006.

LIMA G.J.M.M.; MORES N.; R.L. SANCHES. As diarreias nutricionais na suinocultura. Acta Sci. Vet., v.37, p.17-30, 2009.

MCDONALD, D.E.; PETHICK, D.W.; PLUSKE, J.R.; HAMPSON, D.J. Adverse effects of soluble nonstarch polysaccharide (guar gum) on piglet growth and experimental colibacillosis immediately after weaning. Res. Vet. Sci., v.67, p.245-250, 1999.

MONTAGNE, L.; CAVANEY, F.S.; HAMPSON, D.J. et al. Effect of diet composition on postweaning colibacillosis in piglets. J. Anim. Sci., v.82, p.23642374, 2004

NEPOMUCENO, R.C.; CARVALHO, L.E.; FREITAS, E.R. et al. Inclusão da quirera de arroz em rações de suínos na fase de creche. Rev. Bras. Saúde Prod. Anim., v.12, p.718-728, 2011.

NITZKE, J.A. Terra de arroz. Instituto de Ciência e Tecnologia de Alimentos. UFRGS. 2004. Disponível em:

http://www.ufrgs.br/icta/agronom/arroz/esqarroz.html. Acessado em: 02 dez. 2011.

OLIVEIRA, R.P.; FURLAN, A.C.; MOREIRA, I. et al. Valor nutritivo e desempenho de leitões alimentados com rações contendo silagem de grãos úmidos de milho. Rev. Bras. Zootec., v.33, p.146-156, 2004.
OLIVEIRA, E.L.; LUDKE, M.C.M.M.; LUDKE, J.V. et al. Desempenho de leitões na fase de creche alimentados com rações contendo proteína concentrada de soja. Acta Sci. Anim. Sci., v.34, p.131136, 2012.

PALIPANE, K.B.; SWARNASIRI, C.D.P. Composition of raw and parboiled rice bran from common Sri Lankan varieties and from different types of rice mills. J. Agric. and Food Chem., v.33, p.732734,1985

PLUSKE, J.R.; HAMPSON, D.J.; WILLIAMS, I.H. Factors influencing the structure and function of the small intestine in the weaned pig: a review. Liv. Prod. Sci., v.51, p.215-236, 1997.

ROSTAGNO, H.S.; ALBINO, L.F.T.; DONZELE, J.L. et al. Tabelas Brasileiras para aves e suínos. Composição de alimentos e exigências nutricionais. 3.ed. Viçosa:UFV, 2011. 252p.

SAKOMURA, N.K.; ROSTAGNO, H.S. Métodos de Pesquisa em Nutrição de Monogástricos, Jaboticabal: FUNEP, 2007. 283p.

STATISTICAL ANALYSIS SYSTEM - SAS. SAS language reference. Version 8, Cary: 2001. 1042p.

SILVA, D.J.; QUEIROZ, A.C. Análise de alimentos (métodos químicos e biológicos). Viçosa: Universidade Federal de Viçosa. 2002.

VAN SOEST, P.J.; ROBERTSON, J.B.; LEWIS, B.A. Methods for dietary fiber, neutral detergent fiber, and nonstarch polysaccharides in relation to animal nutrition. J. Dairy Sci., v.74, p.3583-3597, 1991. 